\title{
Overexpression of dihydrofolate reductase is a factor of poor survival in acute lymphoblastic leukemia
}

\author{
JORGE ORGANISTA-NAVA $^{1 *}$, YAZMÍN GÓMEZ-GÓMEZ ${ }^{1 *}$, BERENICE ILLADES-AGUIAR $^{1}$, \\ ANA BERTHA RIVERA-RAMÍREZ ${ }^{2}$, MÓNICA VIRGINIA SAAVEDRA-HERRERA ${ }^{2}$ and \\ MARCO ANTONIO LEYVA-VÁZQUEZ ${ }^{1 *}$
}

${ }^{1}$ Laboratory of Molecular Biomedicine, School of Chemical-Biological Sciences, Guerrero State University, Chilpancingo, Guerrero 39090; ${ }^{2}$ Research Department, State Cancer Institute, Arturo Beltran Ortega, Acapulco, Guerrero 39570, Mexico

Received February 3, 2017; Accepted August 23, 2017

DOI: $10.3892 / \mathrm{ol} .2018 .8429$

\begin{abstract}
Dihydrofolate reductase (DHFR) has an important function in DNA synthesis and is a target of methotrexate, which is a crucial treatment option for acute lymphoblastic leukemia (ALL). However, the number of studies conducted to date on DHFR expression in childhood ALL is limited. The aim of the present study was to determine whether the expression of DHFR is associated with survival in childhood ALL. The expression of DHFR in 96 children with ALL and 100 control individuals was determined using reverse transcription-quantitative polymerase chain reaction. The results of the present study demonstrated that the expression of DHFR mRNA in children with ALL was significantly increased $(\mathrm{P}<0.001)$, compared with that in the control group. In addition, increased levels of DHFR mRNA were observed in patients with B-cell lineage, compared with patients with T-cell lineage ALL $(\mathrm{P}<0.05)$. The Kaplan-Meier estimator analysis revealed that children with ALL who exhibited increased levels of DHFR mRNA had a decreased overall survival time $(\mathrm{P}<0.05)$. It was observed that certain patient prognostic features (including age, sex, white blood cell count and high DHFR expression), are associated with poor survival (log-rank test, $\mathrm{P}<0.05$ ). Therefore, the results of the present study indicated that DHFR upregulation is a factor for poor survival in ALL.
\end{abstract}

Correspondence to: Dr Jorge Organista-Nava or Dr Marco Antonio Leyva-Vázquez, Laboratory of Molecular Biomedicine, School of Chemical-Biological Sciences, Guerrero State University, Avenue Lázaro Cárdenas S/N, University City, Chilpancingo, Guerrero 39090, Mexico

E-mail: joorna@gmail.com

E-mail: leyvamarco13@gmail.com

${ }^{*}$ Contributed equally

Key words: dihydrofolate reductase, acute lymphoblastic leukemia, prognosis, survival

\section{Introduction}

Acute lymphoblastic leukemia (ALL) is the most common childhood cancer and the most frequent cancer in Hispanic children (1). In Mexico, it has been observed that childhood ALL has a relatively higher frequency amongst patients with leukemia, accounting for $\sim 85 \%$ of childhood leukemia, whereas acute myeloid leukemia (AML) represents $\sim 15 \%$ (2). Childhood ALL in Mexico has a mortality rate of 63.7 per million children, one of the highest rates reported globally (2).

Previously, methotrexate (MTX) has been used to target the folate metabolic pathway and is an important component for the treatment of cancer (3) including breast cancer (4), head and neck cancer (5), lung cancer (6) and osteosarcoma (7). Anti-folate therapies work against folate-dependent enzymes by inhibiting de novo pyrimidine and purine biosynthesis, resulting in cell death (8). At present, MTX is used in the chemotherapeutic treatment of patients with ALL. MTX functions as a binding inhibitor of dihydrofolate reductase (DHFR), an enzyme that catalyzes the reduction of DHF to tetrahydrofolate (an essential process for the biosynthesis of purines and thymidylate precursors), and therefore inhibits de novo DNA synthesis $(9,10)$. The molecular mechanisms which underlie MTX resistance are attributed to decreased accumulation of MTX due to impaired transport and decreased retention of MTX, and an increase in DHFR expression (10-12).

Previous studies have demonstrated that increased levels of DHFR mRNA result in resistance to MTX therapy (13-15). However, there are a limited number of studies on the function of DHFR expression in patients with childhood acute leukemia. The purpose of the present study was to determine whether the expression of DHFR is associated with survival of patients with ALL and analyze whether the expression of DHFR may be used as a prognostic marker in acute leukemia.

\section{Materials and methods}

Patients. The present study was a hospital-based retrospective study that analyzed 96 children (60 males, 36 females; mean age, $7.78 \pm 4.97$ years), with ALL validated by bone marrow aspirates and based on the French-American-British morphological criteria cytochemical staining properties and 
immunophenotyping of blast cells $(16,17)$, who were admitted to the Pediatric Oncology Service of the State Cancer Institute (Arturo Beltran Ortega, Acapulco, Guerrero, Mexico), between September 2005 and July 2015. The diagnosis of ALL was further subclassified as T-lineage $\left(\mathrm{CD}^{+}, \mathrm{CD}^{+}\right.$plus $\mathrm{CD}^{+}$or $\mathrm{CD}^{+}$or both) or B-lineage $\left(\mathrm{CD} 22^{+}, \mathrm{CD} 19^{+}, \mathrm{CD} 20^{+}\right.$, $\mathrm{CD} 79 \mathrm{~A}^{+}, \mathrm{HLA}^{-\mathrm{DR}^{+}}$and $\mathrm{CD}^{+}{ }^{+}$) according to the study by Gómez-Gómez et al (18). In addition, 100 healthy individuals were included in the present study as controls (53 males, 47 females; mean age, 10.21 \pm 5.53 years), all of whom had no familial history of cancer. All individuals (patients and controls) included in the study were aged between 1 and 17 years. The study was approved by the Ethics Committee of the State Cancer Institute (Arturo Beltran Ortega, Acapulco, Mexico).

Overall survival (OS) time was determined according to the study by Gómez-Gómez et al (18). Briefly, OS time was determined as the time between the day of registration into the study and the day of mortality (from any cause) or the day of last known contact. Patients with ALL were classified into one of the following two groups: Low-risk, aged between 1 and 10 years with $<50,000$ leucocytes $/ \mathrm{mm}^{3}$ at diagnosis; high risk, aged $<1$ and $>10$ years with $>50,000$ leucocytes $/ \mathrm{mm}^{3}$ at diagnosis.

Specimen collection and total RNA extraction. Bone marrow (patients) and blood (controls) samples from the 196 individuals were obtained and processed, according to the study by Gómez-Gómez et al (18). Different samples were used between patients and controls as bone marrow from healthy individuals was deemed ethically unacceptable. Total RNA was isolated from the bone marrow and/or blood samples using the TRIzol ${ }^{\circledR}$ method (Invitrogen; Thermo Fisher Scientific, Inc., Waltham, MA, USA).

Quantification of $m R N A$ using reverse transcription-quantitative polymerase chain reaction $(R T-q P C R)$. Total RNA $(1 \mu \mathrm{g})$ was converted to cDNA using the Superscript III First-Strand Synthesis System (Invitrogen; Thermo Fisher Scientific, Inc.), according to the manufacturer's protocol. In brief, a $20 \mathrm{ml}$ cDNA reaction mix contained extracted total RNA $(1 \mu \mathrm{g})$, $500 \mathrm{ng}$ oligo (dT) (12-18) and dNTP mix (0.5 mM each). The mixture was heated at $65^{\circ} \mathrm{C}$ for $5 \mathrm{~min}$ and incubated on ice for $3 \mathrm{~min}$. 1x first-strand RT buffer, $5 \mathrm{mM}$ DTT and $5 \mathrm{U}$ of RNase Inhibitor (Invitrogen; Thermo Fisher Scientific, Inc.) were added into each tube. The tubes were incubated at $42^{\circ} \mathrm{C}$ for $2 \mathrm{~min}, 200 \mathrm{U}$ of SuperScript III (Invitrogen; Thermo Fisher Scientific, Inc.) was added and tubes were incubated at $42^{\circ} \mathrm{C}$ for $50 \mathrm{~min}$, and finally $70^{\circ} \mathrm{C}$ for $15 \mathrm{~min}$.

All PCR assays were carried out in triplicate in a $25 \mu \mathrm{l}$ reaction volume, including the following: $5 \mu \mathrm{l}$ cDNA template (500 ng), $12.5 \mu \mathrm{l}$ SYBR-Green PCR Master Mix (SYBR Green PCR Reagents kit; Applied Biosystems; Thermo Fisher Scientific, Inc.), $0.5 \mu \mathrm{M}$ of each oligonucleotide and ultrapure water. The following oligonucleotides were used: DHFR forward, 5'-TTCCTGAGAAGAATCGACCTTTAAA-3' and reverse, 5'-AAGGCATCATCTAGACTTCTGGAAA-3'; hypoxanthine-guanine phosphoribosyltransferase (HPRT) forward, 5'-AAGCTTGCTGGTGAAAAGG-3' and reverse, 5'-AAACATGATTCAAATCCCTGA-3'. The thermocycling conditions were as follows: $95^{\circ} \mathrm{C}$ for $5 \mathrm{~min}$ followed by 40 cycles of $95^{\circ} \mathrm{C}$ for $30 \mathrm{sec}, 60^{\circ} \mathrm{C}$ for $30 \mathrm{sec}$ and $72^{\circ} \mathrm{C}$ for $30 \mathrm{sec}$. All RT-qPCR reactions were performed in 96-well plates using the Applied Biosystems 7500 system (Applied Biosystems; Thermo Fisher Scientific, Inc.). The expression levels of mRNA were determined according to the $2^{-\Delta \Delta C q}$ method (19), using HPRT mRNA expression as a reference. The DHFR level in the ALL samples was defined as the relative value, compared with that of samples from the healthy individuals.

Detection of translocations. The detection of BCR-ABL, ETV6-RUNX1, AML1-ETO and CBFB-MYH11 translocations was realized by PCR and according to the protocol previously reported by Organista-Nava et al (20).

Statistical analysis. SPSS version 20.0 (IBM Corp., Armonk, NY, USA) and GraphPad Prism version 5.0 (GraphPad Software, Inc., La Jolla, CA, USA) software were used to analyze the data obtained. The results are presented as the mean \pm standard deviation or median (25-75\% quartiles). To compare medians and frequencies between groups, $\chi^{2}$ tests were used. The Mann-Whitney U test was used to compare differences in the DHFR mRNA levels between ALL patients and healthy individuals. OS time was determined using the Kaplan-Meier estimator method. Univariate logistic regression analysis was performed to define the risk of relapse, and multivariable logistic regression analysis was used to identify independent risk factors for ALL relapse. $\mathrm{P}<0.05$ was considered to indicate a statistically significant difference.

\section{Results}

Characteristics of the patients and controls. The healthy individuals (controls) exhibited a mean age of $10.21 \pm 5.53$ years and a normal leukocyte count (between 4 and $10 \times 10^{3}$ leukocytes $/ \mathrm{mm}^{3}$; median 8,000 leukocytes $/ \mathrm{mm}^{3}$ ). The patients at diagnosis exhibited a mean age of $7.78 \pm 4.97$ years, with a mean leukocyte count at diagnosis of 18,000 leukocytes $/ \mathrm{mm}^{3}$. Characteristics of the controls and patients are outlined in Table I. Of the patients included in the present study, $44.79 \%$ were classified as low-risk (aged between 1 and 10 years with $<50,000$ leucocytes $/ \mathrm{mm}^{3}$ at diagnosis) and the remaining $55.21 \%$ were classified as high-risk (aged $<1$ and $>10$ years with $>50,000$ leucocytes $/ \mathrm{mm}^{3}$ at diagnosis). The results of the present study demonstrated that B-lineage ALL was observed in $90.63 \%$ patients. Breakpoint cluster region (BCR)/Abelson murine leukemia viral oncogene homolog 1 (ABL) fusion gene was identified in 7.29\% (7/96) patients with ALL. The ETS variant 6 (ETV6)-runt-related transcription factor 1 (RUNX1) rearrangement was revealed in only $0.01 \%$ (1/96) patients with ALL, and 60.42\% (58/96) did not exhibit either the BCR-ABL or ETV6-RUNX1 gene rearrangement. 30 of the 96 patients were not considered for rearrangement analysis as analysis was not possible due to insufficient sample (Table I).

DHFR is significantly expressed patients with ALL. As presented in Table I and Fig. 1, the expression of DHFR was significantly increased in ALL, compared with that in 
Table I. Characteristic and clinical data for patients with ALL compared with those of healthy individuals.

\begin{tabular}{|c|c|c|c|}
\hline Variable & ALL, $n=96$ & Healthy individuals, $\mathrm{n}=100$ & P-value \\
\hline Mean age \pm standard deviation, years & $7.78 \pm 4.97$ & $10.21 \pm 5.53$ & $<0.001^{\mathrm{a}}$ \\
\hline Leukocytes $/ \mathrm{mm}^{3}$ & $18,000(4,700-42,875)^{\mathrm{a}}$ & $8,000(7,000-9,000)^{\mathrm{a}}$ & $<0.001^{\mathrm{a}}$ \\
\hline Sex & & & 0.195 \\
\hline Female & $36(37.50)$ & $47(47.00)$ & \\
\hline Male & $60(62.50)$ & $53(53.00)$ & \\
\hline \multicolumn{4}{|l|}{ Status of participant } \\
\hline Alive & $34(35.42)$ & $100(100.00)$ & - \\
\hline Deceased & $62(64.58)$ & - & \\
\hline \multicolumn{4}{|l|}{ Risk group } \\
\hline Low & $44(45.83)$ & - & - \\
\hline High & $52(54.17)$ & - & \\
\hline \multicolumn{4}{|l|}{ Immunophenotype } \\
\hline B-lineage & $87(90.63)$ & - & - \\
\hline T-lineage & $9(9.37)$ & - & \\
\hline \multicolumn{4}{|l|}{ Chromosomal translocation } \\
\hline ETV6-RUNX1 [t(12;21)] & $1(1.04)$ & - & \\
\hline BCR-ABL $[\mathrm{t}(9 ; 22)]$ & $7(7.29)$ & - & \\
\hline None & $58(60.42)$ & - & \\
\hline Not determined & $30(31.25)$ & - & \\
\hline DHFR level, median (25-75 percentiles) & $9.38(3.39-27.48)$ & $1.07(0.84-1.24)$ & $<0.001^{\mathrm{a}}$ \\
\hline
\end{tabular}

Data are expressed as $\mathrm{n}(\%)$, unless otherwise indicated. ${ }^{\mathrm{P}}<0.05$ vs. healthy individuals, obtained using the $\chi^{2}$ test. ALL, acute lymphoblastic leukemia; low-risk group, aged between 1 and 10 years with $<50,000$ leukocytes $/ \mathrm{mm}^{3}$; high-risk group, aged $<1$ and $>10$ years with $>50,000$ leukocytes/mm³; ETV6, ETS variant 6; RUNX1, Runt-related transcription factor 1; BCR, breakpoint cluster region; ABL, Abelson murine leukemia viral oncogene homolog 1 .

A

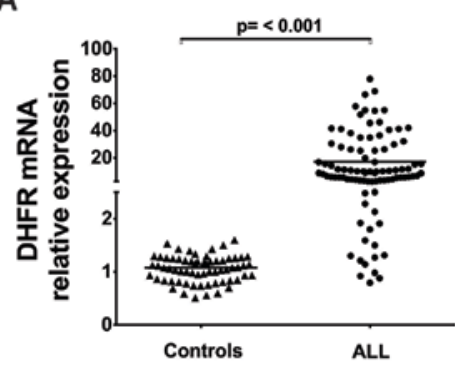

C

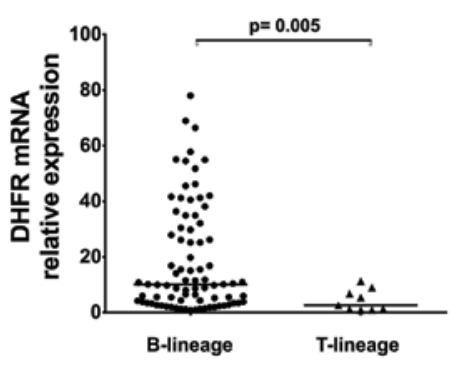

B

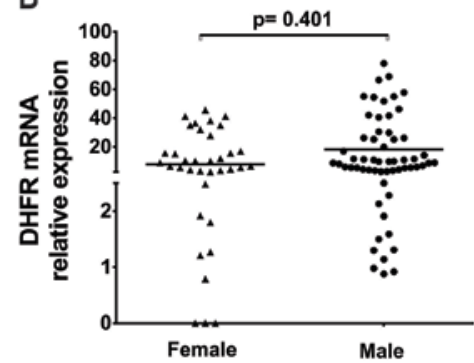

D

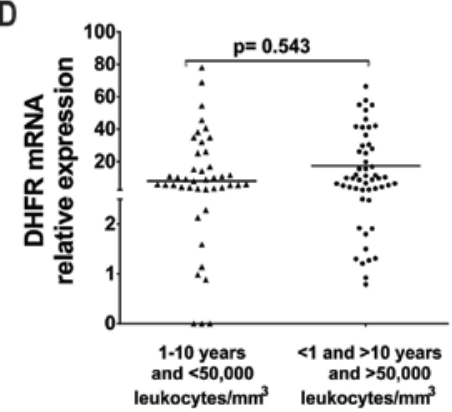

Figure 1. DHFR expression in childhood ALL compared with that in healthy control patients. (A) DHFR mRNA was identified to be significantly increased in patients with ALL compared with in the control patients [median (25-75 percentiles), 9.38 (3.39-27.48); $\mathrm{P}<0.001]$. (B) The level of DHFR mRNA was not identified to be significantly different between male and female patients $(\mathrm{P}>0.05)$. (C) The expression level of DHFR in patient with B-lineage ALL was significantly increased, compared with that in patients with T-lineage ALL [10.10 (3.74-30.87); $\mathrm{P}=0.005]$. (D) The expression levels of DHFR mRNA was not identified as significantly different between patients with ALL classified as low-risk (aged between 1 and 10 years with $<50 \mathrm{~m} 000$ leucocytes $/ \mathrm{mm}^{3}$ ) and patients classified as high-risk (aged $<1$ and $>10$ years with $>50,000$ leucocytes $\left./ \mathrm{mm}^{3}\right)(\mathrm{P}>0.05)$. DHFR, dihydrofolate reductase; ALL, acute lymphoblastic leukemia. 
Table II. Association between DHFR expression level, clinical features and the risk of relapse for patients with ALL.

\begin{tabular}{|c|c|c|c|c|c|c|c|c|c|}
\hline \multirow[b]{2}{*}{ Categories } & \multirow{2}{*}{$\begin{array}{c}\text { Without } \\
\text { relapse, n }(\%)\end{array}$} & \multirow{2}{*}{$\begin{array}{c}\text { With } \\
\text { relapse, n (\%) }\end{array}$} & \multirow[b]{2}{*}{ P-value } & \multicolumn{3}{|c|}{ Univariate analysis } & \multicolumn{3}{|c|}{ Multivariate analysis } \\
\hline & & & & OR & $95 \% \mathrm{CI}$ & P-value ${ }^{a}$ & OR & $95 \% \mathrm{CI}$ & P-value \\
\hline Sex & & & 0.84 & 1.38 & $0.56-3.38$ & 0.49 & 1.43 & $0.55-3.71$ & 0.46 \\
\hline Female & 12 & 24 & & & & & & & \\
\hline Male & 16 & 44 & & & & & & & \\
\hline Risk group & & & $0.04^{\mathrm{a}}$ & 2.91 & $1.16-7.26$ & $0.02^{\mathrm{a}}$ & 3.20 & $1.23-8.29$ & $0.02^{\mathrm{a}}$ \\
\hline Low & 18 & 26 & & & & & & & \\
\hline High & 10 & 42 & & & & & & & \\
\hline DHFR level & & & $0.04^{\mathrm{a}}$ & 2.50 & $1.01-6.16$ & $0.047^{\mathrm{a}}$ & 2.81 & $1.09-7.24$ & $0.03^{\mathrm{a}}$ \\
\hline Downregulated & 17 & 26 & & & & & & & \\
\hline Upregulated & 11 & 42 & & & & & & & \\
\hline
\end{tabular}

${ }^{\text {a }} \mathrm{P}<0.05$ vs. healthy individual, obtained using the $\chi^{2}$ test. ALL, acute lymphoblastic leukemia; low-risk group, aged between 1 and 10 years with $<50,000$ leukocytes $/ \mathrm{mm}^{3}$; high-risk group, aged $<1$ and $>10$ years with $>50,000$ leukocytes $/ \mathrm{mm}^{3}$; OR, odds ratio; CI, confidence interval.
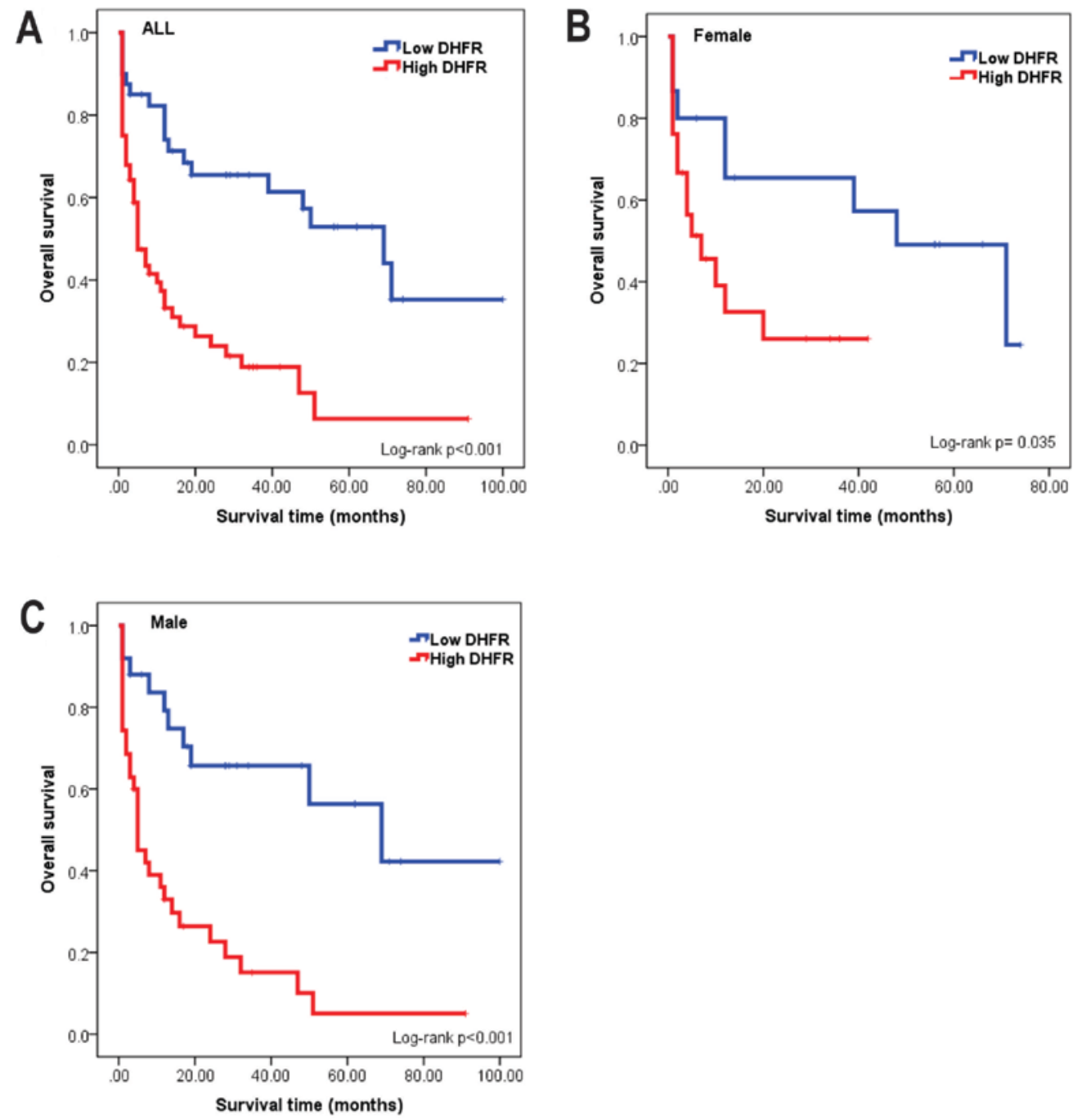

Figure 2. Association between sex, DHFR expression level and prognosis in patients with childhood ALL. (A) OS in patients with ALL exhibiting high or low DHFR expression levels. Patients who exhibited high levels of DHFR expression had a significantly decreased OS, compared with patients with low DHFR expression $(\mathrm{P}<0.001)$. (B) OS in female patients with high and low DHFR expression levels. Female patients with high levels of DHFR mRNA exhibited significantly decreased OS, compared with female patients with low DHFR levels ( $\mathrm{P}=0.035)$. (C) OS in male patients with high and low DHFR expression levels. Male patients exhibiting a high level of DHFR mRNA had a significantly decreased OS, compared with male patients exhibiting low DHFR expression $(\mathrm{P}<0.001)$. DHFR, dihydrofolate reductase; ALL, acute lymphoblastic leukemia; OS, overall survival. 
A

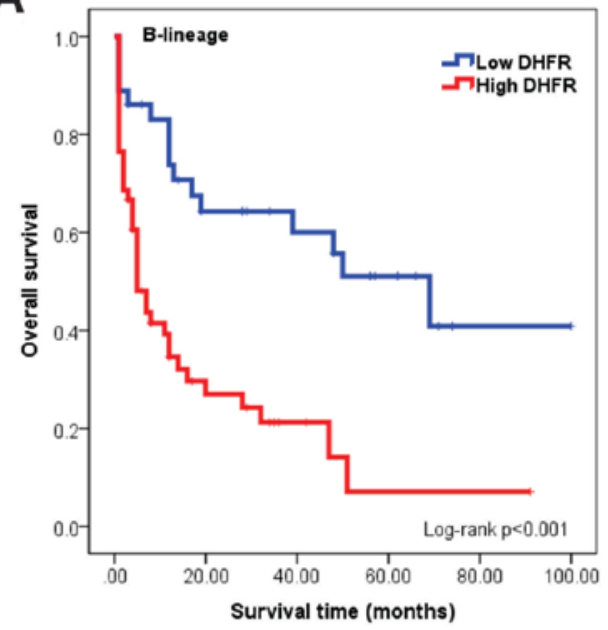

C

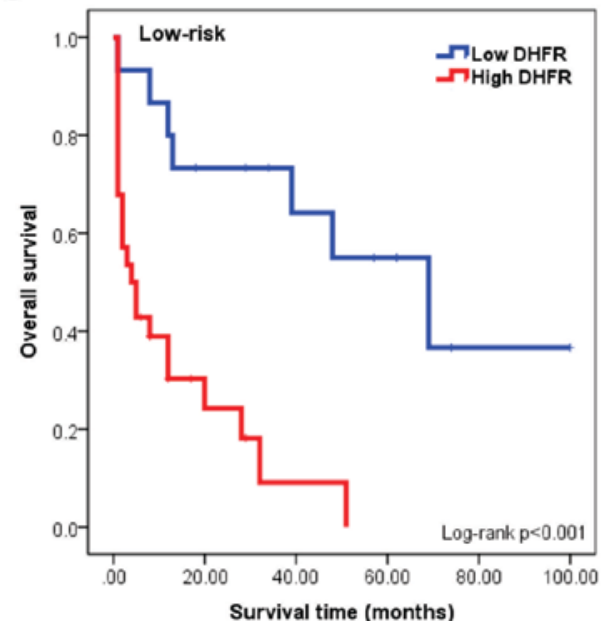

B

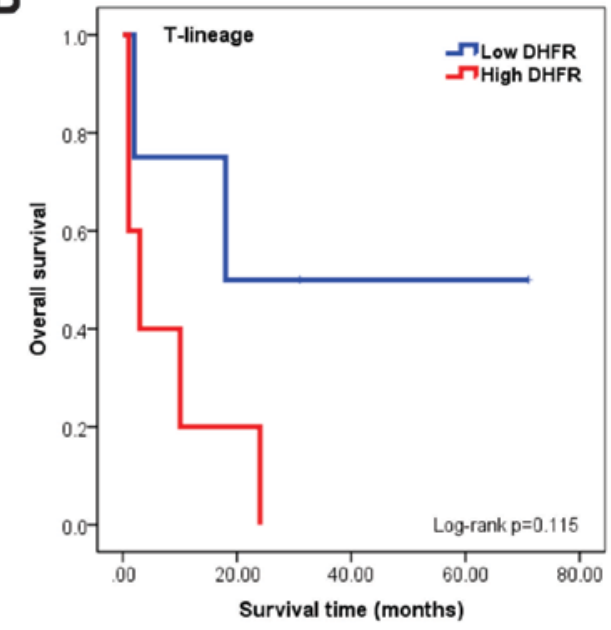

D

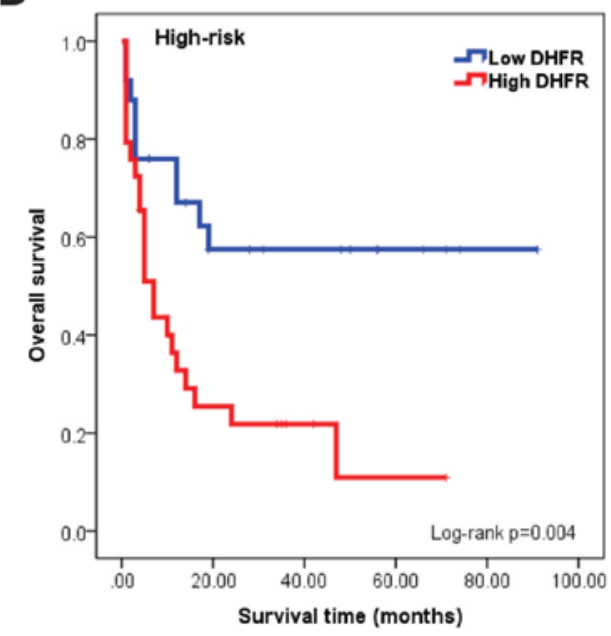

Figure 3. Association between cell lineage (B or T), risk-group, DHFR expression level and prognosis in patients with childhood ALL. (A) The OS was significantly decreased for patients with ALL with B-cell lineage and high DHFR expression, compared with patients with B-cell lineage ALL and low DHFR expression $(\mathrm{P}<0.001)$. (B) The OS was decreased for patients with ALL of the T-cell lineage and high DHFR expression, compared with patients with T-cell lineage ALL and low DHFR expression; however, this difference was not identified to be statistically significant (P>0.05). (C) In the low-risk group (aged between 1 and 10 years with $<50,000$ leucocytes $/ \mathrm{mm}^{3}$ ), the OS was significantly increased for patients with ALL and low DHFR expression, compared with that in patients with high DHFR expression $(\mathrm{P}<0.001)$. (D) In the high-risk group (aged $<1$ and $>10$ years with $>50,000$ leucocytes/mm ${ }^{3}$ ), the OS was significantly decreased for patients with high DHFR expression, compared with those with low DHFR expression (P=0.004). DHFR, dihydrofolate reductase; ALL, acute lymphoblastic leukemia; OS, overall survival.

the controls (Fig. 1A; P<0.001). The median expression of DHFR in the control group was 1.07 -fold (25-75 percentile, 0.84-1.24), whereas the median DHFR expression in the ALL group was 9.38 (3.39-27.48). No statistically significant difference was identified between the male and female patients $(\mathrm{P}=0.401$; Fig. 1B). it was observed that DHFR was significantly increased in patients with B-lineage ALL, compared in with patients with T-lineage ALL $(\mathrm{P}=0.005)$; the mean was 18.63-fold (B-lineage) vs. 4.36-fold (T-lineage) (fold vs. control mean DHFR expression; Fig. 1C). In addition, no statistically significant difference between the low- and high-risk groups was observed ( $\mathrm{P}=0.543$; Fig. 1D).

Patients with ALL who exhibit increased DHFR expression have a higher risk of relapse during treatment. The associations between DHFR expression and the risk of relapse are presented in Table II. The ALL patients were divided into either the high or low DHFR expression groups, using as the median expression level of DHFR (9.38) as the threshold value. A total of 43/96 patients with ALL were classified in the low expression group and the remaining 53/96 were considered to exhibit high levels of DHFR expression. Patients in the high expression group exhibited a 2.81-fold [95\% confidence interval (CI), 1.09-7.24; $\mathrm{P}=0.033$ ] increased risk of relapse during treatment, compared with the low expression group (Table II).

Expression of DHFR and survival in ALL patients. The Kaplan-Meier estimator survival curves were performed to calculate the differences between the survival of ALL patients with high and low expression of DHFR. As presented in Fig. 2A, ALL patients in the high DHFR expression group exhibited poorer survival, compared with the low expression group. Similarly, in Fig. 2B and C, male and female patients with high levels of DHFR expression exhibited poorer survival, compared with patients with low DHFR expression (log-rank test, $\mathrm{P}=0.035$ in females; $\mathrm{P}<0.0001$ in males). 
Patients with B-lineage ALL and high DHFR expression exhibited decreased survival, compared with patients with B-lineage ALL and low DHFR expression (Fig. 3A). Although a decrease in OS was observed in patients with T-lineage ALL and high DHFR expression, compared with patients with T-lineage ALL and low DHFR expression, no significant association was identified (log-rank test, $\mathrm{P}=0.115$; Fig. 3B). In addition, patients with ALL classified as low- or high-risk, and with high DHFR expression, exhibited decreased survival, compared with patients with low DHFR expression (log-rank test; $\mathrm{P}<0.05$; Fig. 3C and D).

\section{Discussion}

MTX is an important component in the chemotherapeutic treatment of several neoplasm types, including childhood ALL (15). The primary causes of MTX-resistance include alterations to its receptor (reduced folate carrier) and increased DHFR expression $(9,21)$. MTX principally exhibits effects by inhibiting DHFR, which has an important function in folate metabolism (11). DHFR is involved in DNA biosynthesis and cell replication $(9,22)$. If there is an increase in the expression of DHFR, DNA becomes more unstable, which may lead to abnormal cell proliferation (23). Therefore, it is important to identify novel biomarkers for patients with a high-risk of treatment failure (relapse), so the appropriate chemotherapeutic scheme may be selected and the survival time of these patients improved.

The overexpression of DHFR in certain cancer cell lines was identified to be a mechanism underlying resistance to MTX chemotherapy $(9,21)$. However, limited information is available regarding the function of DHFR expression in patients with ALL. In the present study, the expression of DHFR was analyzed in samples from patients with ALL, which determined an association between clinical characteristics and patient survival. In addition, the results of the present study revealed that DHFR mRNA was expressed at a significantly increased level in patients with ALL, compared with in the controls $(\mathrm{P}<0.001)$, which was similar to the results of prior studies where high levels of DHFR were observed in acute leukemia $(13,21)$.

To determine the clinical significance of DHFR expression in acute leukemia, a logistic regression analysis was performed to determine associations between the clinical characteristics of patients with ALL and the risk of relapse. The results of the present study demonstrated a significant association between the level of DHFR expression and the risk of relapse of leukemia [odds ratio (OR), 2.50; 95\% CI, 1.01-6.16; $\mathrm{P}=0.047$ ). Concordant with the results of Matheson et al (21), the results of the present study revealed that increased expression of DHFR in patients with ALL increased the risk of relapse. This suggests that DHFR expression levels may be important factor in ALL.

Similar to the results of previous studies $(18,20,24)$, an association between age, sex, leukocyte count at diagnosis and prognosis was identified in the present study. The results of the present study revealed that patients in the high-risk group (aged $<1$ and $>10$ years with $>50,000$ leucocytes $/ \mathrm{mm}^{3}$ at diagnosis) exhibited a poor prognosis, compared with patients in the low-risk group (OR, 2.91; 95\% CI, 1.16-7.26;
$\mathrm{P}=0.02)$; these values have been established by the National Cancer Institute as the values to identify children with poor prognosis (25). Furthermore, DHFR expression was a poor independent prognostic factor (Table II).

The association between DHFR expression levels and the survival of patients with ALL was investigated in the present study. The results demonstrated that patients with high levels of DHFR expression exhibited decreased survival compared with patients with low DHFR expression levels (log-rank, $\mathrm{P}<0.05)$. Similar to the reports of Matherly et al (13), Matheson et al (21) demonstrated an association between the high expression of the DHFR and reduced survival in patients with ALL; this indicates that high levels of DHFR expression are an important prognostic factor in childhood ALL.

The results of the present study have supported the use of genetic factors to complement known biological or disease-based prognostic indicators in ALL. The demonstration of an increase in the expression of the DHFR in ALL is indicative of poor prognosis for patients with ALL.

\section{Acknowledgements}

The authors thank Dr Victor Hugo Garzón Barrientos (State Cancer Institute, Arturo Beltran Ortega, Acapulco, Mexico) for their contribution of biological material and facilitating access to clinical data.

\section{References}

1. Crazzolara R and Bendall L: Emerging treatments in acute lymphoblastic leukemia. Curr Cancer Drug Targets 9: 19-31, 2009.

2. Pérez-Saldivar ML, Fajardo-Gutiérrez A, Bernáldez-Ríos R, Martínez-Avalos A, Medina-Sanson A, Espinosa-Hernández L, Flores-Chapa Jde D, Amador-Sánchez R, Peñaloza-González JG, Alvarez-Rodríguez FJ, et al: Childhood acute leukemias are frequent in Mexico City: Descriptive epidemiology. BMC Cancer 11: 355, 2011.

3. Gonen N and Assaraf YG: Antifolates in cancer therapy: Structure, activity and mechanisms of drug resistance. Drug Resist Updat 15: 183-210, 2012.

4. Bonadonna G, Valagussa P, Moliterni A, Zambetti M and Brambilla C: Adjuvant cyclophosphamide, methotrexate, and fluorouracil in node-positive breast Cancer: The results of 20 years of follow-up. N Engl J Med 332: 901-906, 1995.

5. Guardiola E, Peyrade F, Chaigneau L, Cupissol D, Tchiknavorian X, Bompas E, Madroszyk A, Ronchin P, Schneider M, Bleuze JP, et al: Results of a randomised phase II study comparing docetaxel with methotrexate in patients with recurrent head and neck cancer. Eur J Cancer 40: 2071-2076, 2004.

6. Scagliotti GV, Parikh P, von Pawel J, Biesma B, Vansteenkiste J, Manegold C, Serwatowski P, Gatzemeier U, Digumarti R, Zukin M, et al: Phase III study comparing cisplatin plus gemcitabine with cisplatin plus pemetrexed in chemotherapy-naive patients with advanced-stage non-small-cell lung cancer. J Clin Oncol 26: 3543-3551, 2008.

7. Fuchs N, Bielack SS, Epler D, Bieling P, Delling G, Körholz D, Graf N, Heise U, Jürgens H, Kotz R, et al: Long-term results of the co-operative German-Austrian-Swiss osteosarcoma study group's protocol COSS-86 of intensive multidrug chemotherapy and surgery for osteosarcoma of the limbs. Ann Oncol 9: 893-899, 1998.

8. Visentin M, Zhao R and Goldman ID: The Antifolates. Hematol Oncol Clin North Am 26: 629-648, ix, 2012.

9. Gorlick R, Goker E, Trippett T, Waltham M, Banerjee D and Bertino JR: Intrinsic and acquired resistance to methotrexate in acute leukemia. N Engl J Med 335: 1041-1048, 1996. 
10. de Jonge R, Tissing WJ, Hooijberg JH, et al: Polymorphisms in folate-related genes and risk of pediatric acute lymphoblastic leukemia. Blood 113: 2284-2289, 2009.

11. Assaraf YG: Molecular basis of antifolate resistance. Cancer Metastasis Rev 26: 153-181, 2007.

12. Bertino JR, Göker E, Gorlick R, Li WW and Banerjee D: Resistance mechanisms to methotrexate in tumors. Stem Cells 14: 5-9, 1996.

13. Matherly LH, Taub JW, Wong SC, Simpson PM, Ekizian R, Buck S, Williamson M, Amylon M, Pullen J, Camitta B and Ravindranath Y: Increased frequency of expression of elevated dihydrofolate reductase in T-cell versus B-precursor acute lymphoblastic leukemia in children. Blood 90: 578-589, 1997.

14. Chauhan PS, Bhushan B, Singh LC, Mishra AK, Saluja S Mittal V, Gupta DK and Kapur S: Expression of genes related to multiple drug resistance and apoptosis in acute leukemia: Response to induction chemotherapy. Exp Mol Pathol 92: 44-49, 2012.

15. Dulucq S, St-Onge G, Gagné V, Ansari M, Sinnett D, Labuda D, Moghrabi A and Krajinovic M: DNA variants in the dihydrofolate reductase gene and outcome in childhood ALL. Blood 111: 3692-3700, 2008

16. Bennett JM, Catovsky D, Daniel MT, Flandrin G, Galton DA Gralnick HR and Sultan C: Proposals for the Classification of the Acute Leukaemias French-American-British (FAB) Co-operative Group. Br J Haematol 33: 451-458, 1976.

17. Vardiman JW, Thiele J, Arber DA, Brunning RD, Borowitz MJ, Porwit A, Harris NL, Le Beau MM, Hellström-Lindberg E, Tefferi A and Bloomfield CD: The 2008 revision of the World health organization (WHO) classification of myeloid neoplasms and acute leukemia: Rationale and important changes. Blood 114 937-951, 2009

18. Gómez-Gómez Y, Organista-Nava J, Saavedra-Herrera MV, Rivera-Ramírez A B, Terán-Porcayo M A Del Carmen Alarcón-Romero L, Illades-Aguiar B and Leyva-Vázquez MA: Survival and risk of relapse of acute lymphoblastic leukemia in a Mexican population is affected by dihydrofolate reductase gene polymorphisms. Exp Ther Med 3: 665-672, 2012.
19. Nolan T, Hands RE and Bustin SA: Quantification of mRNA using real-time RT-PCR. Nat Protoc 1: 1559-1582, 2006.

20. Organista-Nava J, Gómez-Gómez Y, Illades-Aguiar B Del Carmen Alarcón-Romero L, Saavedra-Herrera MV, Rivera-Ramírez AB, Garzón-Barrientos VH and Leyva-Vázquez MA: High miR-24 expression is associated with risk of relapse and poor survival in acute leukemia. Oncol Rep 33: 1639-1649, 2015.

21. Matheson EC, Hogarth LA, Case MC, Irving JA and Hall AG: DHFR and MSH3 co-amplification in childhood acute lymphoblastic leukaemia, in vitro and in vivo. Carcinogenesis 28 1341-1346, 2007

22. Abali EE, Skacel NE, Celikkaya H and Hsieh YC: Regulation of human dihydrofolate reductase activity and expression. Vitam Horm 79: 267-292, 2008.

23. Galbiatti AL, Castro R, Caldas HC, Padovani JA Jr, Pavarino ÉC and Goloni-Bertollo EM: Alterations in the expression pattern of MTHFR, DHFR, TYMS, and SLC19A1 genes after treatment of laryngeal cancer cells with high and low doses of methotrexate. Tumor Biol 34: 3765-3771, 2013.

24. Ng SM, Lin HP, Ariffin WA, Zainab AK, Lam SK and Chan LL: Age, sex, haemoglobin level, and white cell count at diagnosis are important prognostic factors in children with acute lymphoblastic leukemia treated with BFM-type protocol. J Trop Pediatr 46: 338-343, 2000.

25. Smith M, Arthur D, Camitta B, Carroll AJ, Crist W, Gaynon P, Gelber R, Heerema N, Korn EL, Link M, et al: Uniform approach to risk classification and treatment assignment for children with acute lymphoblastic leukemia. J Clin Oncol 14: 18-24, 1996. 